\title{
EdITORIAL
}

\section{Embriones híbridos como fuente de células troncales embrionarias}

\author{
Juan Pablo Beca I. \\ Hybrid embryos as a source \\ of embrionic stem cells
}

The HFEA (Human Fertilisations \& Embryology Authority) recently accepted to perform research in hybrid embryos generated by transferring human somatic cell nucleus to cow enucleated oocytes, named cytoplasmatic hybrids. The aim is to obtain a source of embryonic stem cells without the use of human oocytes. The arguments for the approval are to avoid the risk of obtaining human oocytes and that these embryos will not be transferred to a female's womb for its development. Those who oppose the technique argue that it is a manipulation of the beginning of life and a disrespect to the dignity of human life because of the destruction of embryos. Nevertheless, the real nature of this new entity has not been established. Biologically it is an embryo with $99 \%$ of human genome and animal's cytoplasm, not generated from human gametes, it is not a new genome and it will be used only to cultivate stem cells. It does not seem possible to define its nature beyond any doubts. If it were considered as a human embryo it should be respected and protected as every human being. Once more, scientific progress opens new ethical and legal questions that we cannot answer in a definitive way. Researchers are exploring new roads to obtain pluripotential stem cells which should favor the development of innovative therapies. The main objection is the unavoidable destruction of human embryos, although in this case its origin and nature are not clear (Rev Méd Chile 2007; 135: 1367-9).

(Key words: Bioethics; Embryo; Embryonic stem cells; Genome, human)

Centro de Bioética, Facultad de Medicina, Clínica Alemana-Universidad del Desarrollo. Santiago de Chile.

Se ha informado recientemente que la HFEA (Human Fertilisation \& Embryology Authority) en el Reino Unido ha comunicado que no encuentra objeciones a que se realice investigación en embriones híbridos, producidos por la transferencia de núcleos somáticos humanos a óvulos de vacuno enucleados ${ }^{1,2}$. Este anuncio significa que la entidad reguladora británica acogerá, para su

Correspondencia a: Dr. Juan Pablo Beca I. Las Condes 12438, Lo Barnechea. Santiago-Chile. Fax: (562) 2999162. E mail: jpbeca@udd.cl revisión y posible aprobación, proyectos de investigación que empleen esta técnica, siempre que sean científicamente serios y que ofrezcan generar nuevos conocimientos. El objetivo es obtener una fuente de células madre o troncales embrionarias cuyo propósito final es, al igual que en toda investigación con células madre, obtener nuevas posibilidades terapéuticas. Hasta la fecha se han presentado dos proyectos de este tipo y se espera el pronunciamiento de la HFEA para iniciarlos. En muchas personas esta información genera una reacción de sorpresa, temor y fuerte rechazo al imaginar que la investigación científica nos está llevando a la creación de "monstruos" inter- 
especies. ¿Es ésta la realidad? ¿Cuáles son las razones de este tipo de investigación y por qué es aceptada por algunos científicos?

Para analizar el tema desde el punto de vista ético, es necesario primero entender la nueva técnica y su justificación.

Desde hace más de diez años se ha realizado investigación en células madre, lo cual constituye un área importante de investigación en muchos países y parte sustancial de ella se realiza en células troncales de origen embrionario. Estas células se obtienen del macizo celular interno del embrión, lo que lleva necesariamente a su destrucción. Los embriones pueden ser de animales de experimentación o embriones humanos que se obtienen de los sobrantes en Centros de Fecundación Asistida y que son donados por pacientes para su uso en investigación. También es posible producir embriones mediante la transferencia del núcleo de una célula adulta a un óvulo enucleado, lo cual es una clonación por transferencia nuclear que, si se destina a la investigación, recibe el nombre de "clonación terapéutica" 3 . Esta técnica es poco eficiente y requiere un elevado número de óvulos humanos que se obtienen, difícilmente, por donación de pacientes en tratamiento de infertilidad o de mujeres que, sin ser pacientes, venden sus óvulos. Como consecuencia, no hay disponibilidad suficiente de óvulos para los proyectos de investigación y ante esta realidad se ha recurrido a la técnica de transferir núcleos somáticos humanos a óvulos de vaca o de conejo ${ }^{4}$. Se logra así evitar la necesidad de usar óvulos humanos, y se genera un tipo de embrión híbrido que tiene más de 99\% de ADN humano proveniente del núcleo celular del donante y menos de $1 \%$ de ADN mitocondrial del citoplasma del óvulo de la especie animal. A este tipo de híbrido se le llama híbrido citoplasmático o "cybrid embryo" y es genéticamente diferente a embriones híbridos verdaderos, producidos por la fecundación de gametos de dos especies ${ }^{5}$, o a embriones transgénicos que se producen introduciendo los genes de una especie en embriones de otra. Lo autorizado por la HFEA, con la opinión pública mayoritariamente favorable ${ }^{6}$, sólo se refiere a producir embriones híbridos citoplasmáticos. Estos embriones probablemente no son viables y no están destinados a ser transferidos a una mujer, sino a ser fuente de células troncales embrionarias para la investigación.
La razón para investigar en células troncales embrionarias reside en que son pluripotenciales y por lo tanto más factibles de diferenciar en distintas líneas celulares. Sin embargo, a pesar de sus fines científicos beneficiosos en la búsqueda de posibilidades terapéuticas, el uso de células troncales de origen embrionario tiene serias objeciones morales y está legalmente prohibido en muchos países, porque conlleva la destrucción de embriones. La alternativa de investigar en células troncales obtenidas de diversos tejidos adultos no tiene reparos éticos porque no se destruyen embriones humanos, está universalmente permitida y en gran desarrollo, pero se estima que será un camino más lento porque estas células no son pluripotenciales.

Por lo ya expuesto, la producción de células troncales embrionarias a partir de híbridos citoplasmáticos promete ser más eficiente y evita la necesidad de disponer de óvulos humanos. Se argumenta que, con esta alternativa técnica, no se somete a mujeres al riesgo de la donación de óvulos y que los reparos éticos son menores si se compara con las ventajas del progreso en la investigación con fines terapéuticos. Quienes así piensan consideran que producir embriones híbridos citoplasmáticos no constituye un "no respeto" al embrión humano y que la investigación se podría realizar sin reparos, siempre que se asegure que estos embriones se destinarán sólo a la investigación científica. La posibilidad de su transferencia al útero de una mujer para permitir el desarrollo embrionario en ella sería un escenario totalmente diferente y sujeto a un nuevo análisis ético, pero desde ya se considera que serían poco viables y que tendrían un alto riesgo de anomalías del desarrollo.

Los que objetan la generación de híbridos para la investigación consideran que estas técnicas vulneran la dignidad humana, al igual que ocurre con toda investigación en células madre embrionarias humanas, por la necesaria destrucción de embriones. Se argumenta también que, más que un avance científico, se trata de un exceso de manipulación del inicio de la vida y que su aceptación es una apertura para aprobar la generación de otros tipos de híbridos o quimeras, con fines aún desconocidos. Otra clase de rechazo es el de quienes piensan que los conocimientos adquiridos, a partir de la investigación en células 
madre obtenidas de embriones híbridos, podrían no ser extrapolables a lo que ocurre con células o tejidos que son genéticamente $100 \%$ humanos.

La pregunta que no asume ni responde la HFEA es cuál es la naturaleza de esta nueva entidad biológica producida por transferencia nuclear entre especies diferentes. Se trata de un embrión con un genoma 99\% humano y citoplasma de vacuno, que no tiene origen gamético, que no es un nuevo genoma, que no se sabe si es viable ante una eventual transferencia y que está destinado a ser cultivado para producir células pluripotenciales con genoma humano. No es exactamente un clon de quien aportó el núcleo somático, pero es morfológicamente un cigoto y no hay diferencias cualitativas entre un híbrido citoplasmático y un embrión generado por transferencia nuclear en la misma especie ${ }^{7}$. Por lo tanto debe ser considerado biológicamente un embrión humano, aunque tenga una mínima proporción de ADN mitocondrial de vacuno y aunque sea destinado de manera exclusiva a ser cultivado para la producción de células troncales. Sin embargo, no parece posible definir su naturaleza con claridad absoluta. Las consecuencias éticas de esta definición son esenciales pues, si se le considera sólo como un tipo especial de célula, no correspondería tener hacia ella más obligaciones que las que se tienen con otras células o tejidos. Pero, si se le considera un embrión humano, se le debe reconocer su derecho a ser respetado y protegido como a todo ser humano, aceptando que existen dudas y polémicas no resueltas acerca de los deberes que tenemos hacia el embrión temprano o preimplantacional.

\section{REFERENCIAS}

1. Dyer C. HFEA is to launch public debate on hybrid animal-human embryos. BMJ 2007; 334: 925.

2. HFEA. Statement on its decision regarding hybrid embryos. Consultado el 5 septiembre de 2007.

3. Evers K. European Perspectives on Therapeutic Cloning. N Engl J Med 2002; 346:1579-82.

4. Illmensee K, Levanduski M, Zavos PM. Evaluation of the embryonic preimplantation potential of hu-
Otro problema se plantea por el hecho de investigar a partir de una manipulación reproductiva inter-especies. Aun cuando en rigor no es una intervención antinatural de la reproducción, sino la búsqueda de alternativas para producir células troncales embrionarias, la información de prensa reporta que se han formulado críticas de parte de quienes no aceptan moralmente ninguna forma de manipulación o intervención de la reproducción humana. La dificultad reside en que la oposición en bloque a todo este tipo de investigación tiene el riesgo de obstaculizar la investigación en células madre embrionarias, la cual es una esperanza para encontrar, en menor plazo, alternativas de tratamiento para una amplia gama de enfermedades que hoy son incurables.

Una vez más, el avance de la ciencia y la tecnología nos enfrenta a temas nuevos y abre interrogantes en el ámbito científico, ético y legal a las cuales es muy difícil responder de manera definitiva. La Bioética está llamada a contribuir a la reflexión racional, de una manera amplia y plural, evitando llegar a conclusiones anticipadas $\mathrm{o}$ insuficientemente fundamentadas. Aunque este nuevo tema planteado puede ser visto como una forma de manipulación del inicio de la vida humana, la decisión de la HFEA no es tan radical como parece ${ }^{3}$. En lo fundamental se le considera como una alternativa para obtener células pluripotenciales que permitirán avanzar en la investigación científica con fines terapéuticos. Nuevamente la objeción principal es la necesaria destrucción de embriones humanos, aunque en este caso su origen es diferente y su naturaleza no está clara.

man adult somatic cells via an embryo interspecies bioassay using bovine oocytes. Fertil Steril 2006; 85: Suppl 1: 1248-60.

5. Editorial. Animal-human hybrid-embryo research. Lancet 2007; 370: 909.

6. Kмietowicz Z. Public support for hybrid embryos rises with knowledge, poll shows. BMJ 2007; 335: 466-7.

7. HFEA. Hybrids and Chimeras Consultation. www. hfea.gov.uk/en/1517.html, April 2007. 